\title{
CÁC NHÂN TỐ ẢNH HƯởNG ĐẾN SƯ GẮN BÓ CỦA NHÂN VIÊN VỚI TỐ CHỨC: NGHIÊN CỦU THỰC NGHIÊM TẠI CÔNG TY TNHH SẢN XUẤT VÀ KINH DOANH THÉP ĐÔNG Á
}

\author{
Nguyễn Thị Mo', Hoàng Văn Huệ, Nguyễn Thị Mý \\ Truờng Đại hoc Su pham kỹ thuật Hung Yên
}

Ngày tòa soạn nhận được bài báo: 16/04/2018

Ngày phản biện đánh giá và sửa chữa: 09/05/2018

Ngày bài báo được xét duyệt đăng: 15/05/2018

\section{Tóm tắt:}

Nghiên cứu này tập trung phân tích các nhân tố ảnh hưởng đến sư gắn bó của nhân viên đối với công ty TNHH Sản xuất và kinh doanh thép Đông Á. Số liệu của nghiên cúu được thu thập thông qua phát phiểu khảo sát 230 cán bộ, nhân viên. Nghiên cưu sử dụng phương pháp kiểm định độ tin cây bắng hệ số Cronbach's anpha, phân tích nhân tố khám phá và hồi quy tuyến tính. Kêt quả cho thấy, mức độ gắn bó của nhân viên với công ty phục thuộc vào bốn nhân tố: thu nhập và phúc lợi, co hội đào tạo và thăng tiến, điều kiện làm việc và tính ôn định trong công viẹcc. Trong đó nhân tố thu nhập và phúc lợi có tác động mạnh nhất đển sự gắn bó của cán bộ, nhân viên tại công ty.

Tù khóa: sự gắn bó của nhân viên.

\section{I. Đặt vấn đề}

Để tồn tại và phát triển trong sự cạnh tranh quyết liệt của thương trường, chủ doanh nghiệp cần có những người luôn sát cánh, cùng nghĩ và cùng làm để đạt được các mục tiêu kinh doanh của doanh nghiệp. Hay nói khác hơn làm sao để nguồn nhân lực này gắn kết và trung thành với tổ chức là vô cùng quan trọng. Khi nhân viên rời bỏ, công ty phải tốn thời gian tìm kiếm người thay thế cũng như chi phí đào tạo, bên cạnh đó còn phải đối đầu với sự rò rỉ thông tin, công nghệ, khách hàng và nghiêm trọng hơn là làm xấu đi hình ảnh của công ty. Vì vậy, công ty TNHH Sản xuất và kinh doanh thép Đông Á cần phải tìm hiều các yếu tố làm ảnh hưởng đến sự gắn bó của nhân viên mình trên cơ sở đó sẽ xem xét, đánh giá và có những hướng đi phù hợp trong việc nâng cao sự trung thành, gắn bó của nhân viên.

\section{Cơ sở lý thuyết và phương pháp nghiên cứu 1. Cơ sở lý thuyết}

Sự gắn bó là ý định gắn bó lâu dài với tổ chức, do đó tổ chức thường thúc đẩy cam kết trong nhân viên của họ lên cao để đạt được sự ổn định và giảm chi phí. Sự gắn kết của nhân viên đối với tổ chức đã dẫn hướng cho sự thành công của tổ chức và cũng chính các nhân viên trung thành, tự hào, yêu mển tổ chức sẽ giúp tổ chức đạt được những mục tiêu kinh doanh to lớn bằng việc làm thỏa mãn khách hàng, duy trì năng suất và hiệu quả công việc nhằm đạt được các mục tiêu tài chính. Sự gắn bó của nhân viên với tổ chức là chủ đề thu hút nhiều sự quan tâm của các nhà khoa học trong và ngoài nước, nó được xem như là một chủ đề quan trọng trong lĩnh vực hành vi tổ chức và tâm lý tổ chức. Trong thời gian qua, các nhà khoa học trên thế giới đã nghiên cứu và đưa ra nhiều quan điểm khác nhau về gẳn bó của nhân viên với tố chức hay cam kết của nhân viên với tổ chức.

Meyer và Allen (1990), định nghĩa gắn bó với tổ chức là trạng thái tâm lý buộc chặt cá nhân với tổ chức. Tác giả đã chú trọng ba trạng thái tâm lý của nhân viên khi gắn kết với tổ chức. Nhân viên có thể trung thành với tổ chức, xuất phát từ tình cảm thực sự của họ, họ sẽ ở lại với tổ chức dù nơi khác trả lương cao hơn, điều kiện làm việc tốt hơn; họ chỉ có thể trung thành với tổ chức chỉ vì họ không có cơ hội kiếm được công việc tốt hơn; và họ trung thành với tổ chức vì những chuẩn mực đạo đức mà họ theo đuổi. Sự hài lòng công việc là những đánh giá dựa trên những nhận thức và tình cảm của nhân viên về niềm tin và cảm xúc tích cực của họ đối với công việc đó (Slack và cộng sự, 2010). Sự gắn bó của nhân viên với tổ chức được thể hiện ở hai khía cạnh: thứ nhất là gắn bó hành vi, cá nhân mong muốn sẽ nhận được phần thưởng từ tổ chức hay ngược lại thực hiện nghĩa vụ của mình với tổ chức đó theo cách "một người tự trói buộc mình bằng chính hành động của anh ta" (Mowday và cộng sự, 1979); thứ hai, là gắn bó thái độ: Là sức mạnh tương đồng về sự đồng nhất của nhân viên với tổ chức và sự tham gia tích cực của nhân viên trong một tổ chức nhất định (Porter\& cộng sự, 1974). Sự gắn bó xuất hiện và phát triển chậm nhưng chắc chắn theo thời gian khi cá nhân đó suy nghĩ về mối quan hệ giữa họ và tổ chức. Ngược lại, sự hài lòng trong công việc là một thước đo không bền vững theo thời gian, nó phản ánh những hành vi tức thời đối với các vấn đề cụ thể như lương, thưởng, giám sát.

Theo Man Power (2002), thì sự gắn bó bao gồm: (1) sự sã̃n lòng giới thiệu công ty của mình như một nơi làm việc tốt; (2) sẵn lòng giới thiệu các sản phẩm và dịch vụ của công ty; (3) Có ý định gắn bó lâu dài với công ty. Kanter (1968) cho rằng "gắn bó với tổ chức như sự tự nguyện của người lao động để công hiến năng lượng và sự trung thành với một tổ chức". Gắn bó với tổ chức là mối quan hệ đa chiều trong tự nhiên, liên quan đến lòng trung thành của nhân viên cho tồ chức, sẵn sàng nỗ lực cho tổ chức, mục tiêu và giá trị hợp thức của tổ chức và mong muốn duy trì với tổ chức (Bateman, 1984). Sự gắn bó với tổ chức là lời hứa của cá nhân với tổ chức bao gồm ý thức về gắn bó với công việc, lòng trung 
thành và niềm tin về các giá trị của tổ chức $\left(\mathrm{O}^{\prime}\right.$ Reilly \&Chatman (1986), Northcraft\&Neale (1996)).

Trong thực tiễn của Việt Nam, nghiên cứu của Trần Thị Kim Dung (2005) thông qua số liệu sơ cấp của các cuộc điều tra tại 86 doanh nghiệp ở Việt Nam chỉ ra yếu tố ảnh hưởng đến mức độ gẳn bó là công việc, cơ hội đào tạo và thăng tiến. mồi trường và không khí làm việc, thu nhập. Kết quả cũng chỉ ra rằng yếu tố ảnh hưởng lớn nhất đến mức độ gắn bó của nhân viên là môi trường không khí làm việc, yếu tố ít ảnh hưởng nhất đến mức gắn bó của nhân viên chính là cơ hội đào tạo và thăng tiến.

Phạm Thế Ânh (2009), chỉ ra mức độ gắn bó của người lao động với doanh nghiệp cho thấy cơ hội phát triển, chế độ đãi ngộ và lương thưởng và hệ thống bản mô tả công việc là ba nhân tố quan trọng tác động cùng chiều đến sự gắn kết doanh nghiệp.

\section{Mô hình và giả thuyết nghiên cứu}

Trong những nghiên cứu của Singh (2004), Mowday và cộng sự (1979) đã đưa ra 8 nhân tố ảnh hưởng đến mức độ gắn bó của nhân viên với công ty: (1) môi trường và điều kiện làm việc; (2) lương bồng hậu hĩnh, (3) cơ hội thăng tiến, (4) Văn hóa tổ chức, (5) Ý thức sở hữu, (6) Giờ giấc làm việc linh động, (7) Mối quan hệ với cấp trên, (8) sự cần bằng cuộc sông và công việc. Dựa trên những cơ sở lỷ thuyết nổi tiếng trên, nghiên cứu của Trần Thị Kim Dung (2005), Trần Thị Kim Dung và Nguyễn Thị Mai Trang, Phạm Thế Anh và tình hình nhân sự thực tế tại công ty $\mathrm{TNHH}$ sản xuất và kinh doanh thép Đông, Á tác giả quyết định điều chỉnh và đề xuât một số nhân tố cơ bản tác động đến sự gắn bó của nhân viên với công ty để xây dựng nên mô hình nghiên cứu.

Giả thuyết nghiên cứu:

H1: Bản chất công việc có quan hệ cùng chiều với sự gắn bó của nhân viên với tổ chức

H2: Đào tạo và thăng tiến có quan hệ cùng chiều với sự gắn bó của nhân viên với tổ chức;

H3:Môi quan hệ nơi làm việc có quan hệ cùng chiều với sự gắn bó của nhân viền với tổ chức;

H4: Thu nhập và phúc lợi có quan hệ cùng chiều với sự gắn bó của nhân viền với tổ chức;

H5: Điều kiện làm việc có quan hệ cùng chiều với sự gắn bó của nhân viên với tổ chức;

H6: Tính ổn định trong công việc có quan hệ cùng chiều với sự gắn bó của nhân viên với tô chức;

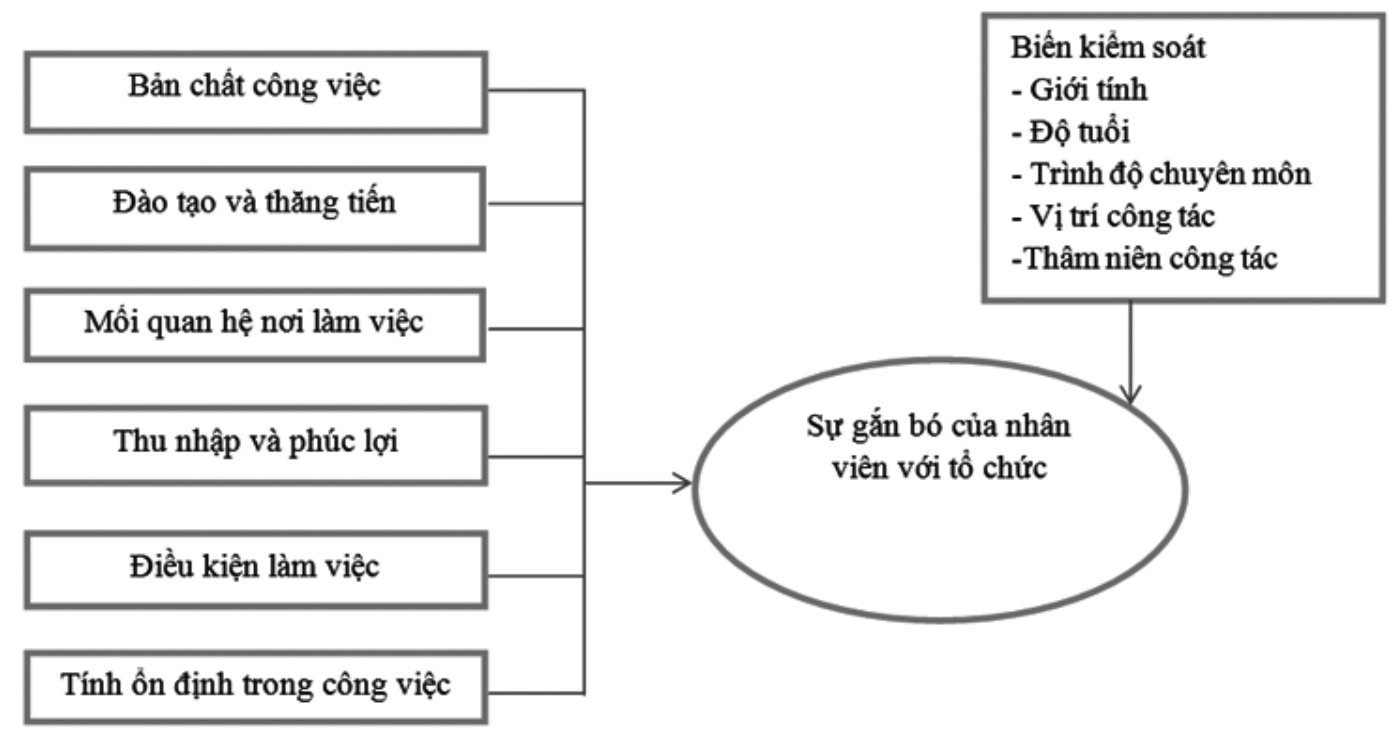

Hình 1.1. Mô hình nghiên cứu đề xuất

(Nguồn: Tác giả đề xuất)

\section{Phương pháp nghiên cứu}

Nghiên cứu này được thực hiện trên 2 phương pháp nghiên cứu: nghiên cứu định tính và nghiên cứu định lượng. Thang đo Likert với 5 cấp độ được sử dụng trong bảng câu hỏi khảo sát:

(1) Hoàn toàn không đồng ý; (2) Không đồng ý; (3) Bình thường; (4) Đồng ý; (5) Hoàn toàn đồng ý. Thang đo đo lường 7 nhân tố với 37 quan sát. Trong đó các nhân tố như bản chất công việc (Congviec) có 6 quan sát; đào tạo và thăng tiến (dtvatt) có 5 quan sát; quan hệ nơi làm việc(qhnlv) có 7 quan sát; thu nhập và phúc lợi (tnvapl) Điều kiện làm việc (dklv) có 6 quan sát; tính ốn định trong công việc (ondinhcv) có 4 quan sát, Biến phụ thuộc có 5 quan sát. Các thông tin cá nhân như giới tính, độ tuổi, thu nhập, trình độ học vấn cũng được thiết kế trong bảng câu hỏi theo thang đo định tính, định lượng dùng để sàng lọc và thu thập thông tin của các ứng viên.

Dữ liệu thu về được làm sạch, xử lý sơ bộ với sự hỗ trợ của phần mềm SPSS 20.0. Để khẳng định rằng các thang đo lường đảm bảo về độ tin cậy, độ hiệu lực hội tụ và độ hiệu lực phân biệt, nghiên cứu thực hiện 2 bước: tính toán độ tin cậy Cronbach's alpha và phân tích nhân tố khám phá EFA cho tất cả thang đo bằng thủ tục Principal Axis Factoring với phép quay Promax. Để đánh giá mô hình đề xuất, các điểm nhân tố sẽ được tính, sau đó 
phương pháp hồi quy bội sẽ được sử dụng.

\section{Kết quả nghiên cứu và thảo luận}

1. Đánh giá độ tin cậy các thang đo bằng hệ số Cronbach's alpha

Kết quả kiểm định độ tin cậy thang đo các biến độc lập (Phụ lục 1) cho thấy Cronbach's Alpha là $0,872>0,6$ và hệ số tương quan biến tổng phải lớn hơn 0,3 mới có thể đưa vào phân tích nhân tố tiếp theo. Do vậy, cần loại các quan sát congviec3, đtvatt2, qhnlv7, dklv1, dklv6 ra khỏi mô hình. Kết quả cuối cùng còn 27 quan sát được đưa vào phân tích nhân tố tiếp theo.
Kết quả kiểm định thang đo các biến phụ thuộc (Phụ lục 02) cho thấy Cronbach's Alpha là $0,898>0,6$ và các hệ số tương quan biến tông đều lớn hơn 0,3 nên đạt yêu cầu và đưa vào phân tích nhân tố tiếp theo.

\section{Phân tích nhân tố khám phá - EFA}

Sau khi kiểm định độ tin cậy của thang đo thông qua hệ số Cronbach's Alpha, các thang đo được đánh giá tiếp theo bằng phương pháp phân tích nhân tố khám phá (EFA). Phương pháp trích yếu tố được sử dụng là Principal components với phép quay Varimax.

\section{Bảng 2.1. Kết quả phân tích nhân tố khám phá của biến độc lập}

\section{KMO and Bartlett's Test}

\begin{tabular}{ll}
\hline Kaiser-Meyer-Olkin Measure of Sampling Adequacy. \\
& Approx. Chi-Square \\
Bartlett's Test of Sphericity & Df \\
& Sig.
\end{tabular}

Kết quả phân tích nhân tố cho thấy phân tích nhân tố thích hợp với dữ liệu nghiên cứu do có hệ số $\mathrm{KMO}$ là $0,813(0,5<\mathrm{KMO}<1)$. Đồng thời kết quả kiểm định Bartlett's với mức ý nghĩa sig. Là 0,000 nhỏ hơn 0,05. Các biến quan sát trong tổng thể có mối tương quan với nhau và chứng tỏ dữ liệu dùng để phân tích nhân tố là hoàn toàn thích hợp.

\section{Bảng 2.2. Kết quả EFA của biến phu thuộc \\ KMO and Bartlett's Test}

\begin{tabular}{|c|c|c|}
\hline \multicolumn{2}{|c|}{ Kaiser-Meyer-Olkin Measure of Sampling Adequacy. } & .795 \\
\hline & Approx. Chi-Square & 1225.902 \\
\hline \multirow[t]{2}{*}{ Bartlett's Test of Sphericity } & Df & 10 \\
\hline & Sig. & .000 \\
\hline
\end{tabular}

\begin{tabular}{|l|r|}
\hline & Hệ số tải nhân tố \\
\hline 1. Thật khó rời khỏi công ty này ngay cả khi muốn & .952 \\
2. Cảm thấy công ty như là ngôi nhà thứ hai của mình & .944 \\
3. Hạnh phúc khi sử dụng thời gian làm việc đến cuối đời với công ty & .820 \\
4. Cuộc sống sẽ xáo trộn nếu rời bỏ công ty ngay bây giờ. & .819 \\
5. Công ty xứng đáng với lòng trung thành & .651 \\
Eigen value & 3.565 \\
Phương sai trích (\%) & 71.304 \\
Phương sai trích tích lũy $(\%)$ & 71.304 \\
\hline
\end{tabular}

Phân tích EFA với phương sai trích nhân tố Principal compoment, phép quay Varimax trích được một nhân tố với 5 biên quan sát và phương sai trích tích lũy được 71,304\% (> 50\%) là đạt yêu cầu.

Qua phân tích EFA với tất cả các chỉ báo, kết quả cho thấy sáu nhân tố độc lập: bản chất công việc, đào tạo và thăng tiến, mối quan hệ nơi làm việc, thu nhập và phúc lợi, điều kiện làm việc, tính ôn định trong công việc và một nhân tố phụ thuộc: sự gắn bó của nhân viên với tổ chức. Các hệ số tải nhân tố đều đạt yêu cầu là lớn hơn 0.5 nên các chỉ báo có ý nghĩa, do đó tiếp tục đưa vào phân tích các bước tiếp theo.

\section{Phân tích hồi quy}

Phân tích hồi quy được thực hiện với 6 biến độc lập, tác giả đã tiến hành kiểm tra các giả định. Với giả thuyết ban đầu cho mô hình lý thuyết hồi quy có dạng như sau:

$\mathrm{Y}=\beta_{0}+\beta_{1} \mathrm{X}_{1}+\beta_{2} \mathrm{X}_{2}+\beta_{3} \mathrm{X}_{3}+\beta_{4} \mathrm{X}_{4}+\beta_{5} \mathrm{X}_{5}+\beta_{6} \mathrm{X}_{6}+\mathrm{e}_{\mathrm{i}}$

Trong đó: $\mathrm{Y}$ là gắn bó với tổ chức $\mathrm{X}_{1}$ : Bản chất công việc $\mathrm{X}_{2}$ : Đào tạo và thăng tiến 
$\mathrm{X}_{3}$ : Quan hệ nơi làm việc

$\mathrm{X}_{4}$ : Thu nhập và phúc lợi

$\mathrm{X}_{5}$ : Điều kiện làm việc

$\mathrm{X}_{6}$ : Tính ổn định trong công việc

$\mathrm{e}_{i}$ : Sai số ngẫu nhiên

$\beta_{0}, \beta_{1}, \beta_{2}, \beta_{3}, \beta_{4}, \beta_{5}, \beta_{6}$ : Các hệ số hồi quy

Bảng 3.1. Mức độ giải thích của mô hình

\begin{tabular}{|l|c|r|r|r|r|}
\hline $\begin{array}{c}\text { Mô } \\
\text { hình }\end{array}$ & $\mathrm{R}$ & \multicolumn{1}{|c|}{$\mathrm{R}^{2}$} & $\begin{array}{c}\mathrm{R}^{2} \text { hiệu } \\
\text { chỉnh }\end{array}$ & $\begin{array}{c}\text { Độ lệ̂ch } \\
\text { chuẩn }\end{array}$ & $\begin{array}{l}\text { Durbin- } \\
\text { Watson }\end{array}$ \\
\hline 1 & $.548^{\mathrm{a}}$ & .301 & .282 & .49053 & 1.770 \\
\hline
\end{tabular}

(Nguồn: tác giả tổng hợp và xủ lý trên SPSS)
Bảng 3.1 cho thấy, $\mathrm{R}^{2}$ hiệu chỉnh bằng 282 nghĩa là $28,2 \%$ sự biến thiên của ganbo (sự gắn bó của nhân viên với tổ chức) được giải thích bởi sự biến thiên của 6 biến độc lập (bản chất công việc, đào tạo và thăng tiến, quan hệ nơi làm việc, thu nhập và phúc lợi, điểu kiện làm việc, tính ổn định trong công việc). Ngoài ra kiểm định Durbin-Watson $\mathrm{d}$ $=1,770(1<\mathrm{d}<3)$, không có tương quan giữa các phần dư.

Bảng 3.2. Mức độ phù hơp của mô hình ANOVA

\begin{tabular}{|l|l|r|r|r|r|r|}
\hline \multicolumn{2}{|c|}{ Mô hình } & \multicolumn{1}{c|}{ Tổng bình phương } & \multicolumn{1}{c|}{ Df } & Trung bình bình phương & F & Sig. \\
\hline \multirow{4}{*}{1} & Hồi quy & 22.661 & 6 & 3.777 & 15.696 & $.000^{\mathrm{b}}$ \\
\cline { 2 - 7 } & Phần dư & 52.697 & 219 & .241 & & \\
\cline { 2 - 8 } & Tồng & 75.357 & 225 & & & \\
\hline
\end{tabular}

a. Biến phụ thuộc: ganbo

b. Biến độc lập: (Hằng số), ondinhcv, qhnlv, congviec, dklv, tnvapl, dtvatt

(Nguồn: tác giả tổng hợp và xủ lý trên SPSS)

Qua Bảng 3.2 cho thấy trị số $\mathrm{F}$ có mức ý nghĩa Sig. $=0.000(<0,05)$ mô hình hồi quy tuyến tính đưa ra là phù hợp với dữ liệu thu thập được và các biến đều có ý nghĩa trong thống kê.

Bảng 3.3. Thống kê phân tích các hệ số hồi quy

\begin{tabular}{|c|c|c|c|c|c|}
\hline \multicolumn{2}{|r|}{ Mô hình } & \multicolumn{2}{|c|}{ Hệ số chưa chuẩn hóa } & \multirow[t]{2}{*}{ Hệ số chuẩn hóa } & \multirow[t]{2}{*}{$\mathrm{T}$} \\
\hline \multirow{8}{*}{1} & (Constant) & $\mathrm{B}$ & Độ lệch chuẩn & & \\
\hline & Hằng số & 2.817 & .316 & & 8.926 \\
\hline & congviec & -.362 & .204 & -.293 & -1.776 \\
\hline & Dtvatt & 1.040 & .515 & .844 & 2.021 \\
\hline & Qhnlv & -.868 & .167 & -.678 & -5.183 \\
\hline & Tnvapl & .366 & .467 & .299 & .785 \\
\hline & Dklv & .139 & .278 & .109 & .499 \\
\hline & ondinhcv & .053 & .322 & .042 & .165 \\
\hline
\end{tabular}

(Nguồn: tác giả tổng hợp và xử lý trên SPSS)

Từ Bảng 3.3 cho thấy mô hình hồi quy có dạng như sau: $\mathrm{Y}=2,817+1,040 \mathrm{X}_{2}+0,366 \mathrm{X}_{4}+0,139 \mathrm{X}_{5}+0,053 \mathrm{X}_{6}$

Hay gắn bó của nhân viên với tổ chức $=$ $2,817+1,040 *$ đào tạo và thăng tiến $+0,366 *$ thu nhập và phúc lợi $+0,139 *$ điều kiện làm việc + 0,053 *ổn định công việc.

Kết quả hồi quy cho thấy, sau khi loại bỏ các nhân tố tác động không có ý nghĩa thống kề, kết quả cho thấy có 4 nhân tố tác động đến sự gắn bó của nhân viên tại công ty $\mathrm{TNHH}$ sản xuất và kinh doanh thép Đông Á đó là cơ hội đào tạo và thăng tiến, thu nhập và phúc lợi, điều kiện làm việc và tính ổn định công việc.

Dựa vào kết quả nghiên cứu, Ban giám đốc công ty cần có phương hướng cụ thể tác động vào những nhân tố có ảnh hưởng nhiều đến sự gẳn bó của nhân viên như thu nhập và phúc lợi, cơ hội đào tạo và thăng tiến, điều kiện làm việc và tính ổn định công việc nhằm đem lại hiệu quả cao trong công tác giữ chân nhân viên.

\section{Kết luận và kiến nghị \\ 1. Kết luận}

Kết quả phân tích cho thây có 4 nhân tố tác động cùng chiều đến sự gắn bó của nhân viên tại cồng ty TNHH sản xuất và kinh doanh thép Đông Á trong đó nhân tố ảnh hưởng lớn nhất chính là thu nhập và phúc lợi. Đây cũng là mối quan tâm hàng đầu của người lao động tại tất cả các doanh nghiệp. Có thể nói rằng nghiên cứu này là cơ sở khoa học quan trọng nhằm giúp Ban lãnh đạo công ty hoạch định chính sách và đề ra các biện pháp hữu hiệu hơn nữa để hoàn thiện công tác quản trị nguồn nhân lực 
và nâng cao mức độ gắn bó của nhân viên đối với công ty.

\section{Kiến nghị}

Nhằm tăng cường sự gắn bó của nhân viên với công ty, tác giả đề xuất các kiến nghị sau:

- Nhân tố thu nhập và phúc lợi: Đây là mối quan tâm hàng đầu của cán bộ, nhẩn viên, do vậy công ty cần có hình thức trả lương linh hoạt, đánh giá định kỳ theo quý, tháng để nâng lương cho người lao động. Cần khen thưởng đúng người, đúng việc xứng đáng với thành tích mà nhân viên đã cống hiến cho công ty. Đồng thời công ty cần xem xét xây dựng lại hệ thống thang bảng lương, xây dựng KPI và trả lương theo phương pháp 3Ps, đảm bảo sự công bằng giữa các nhân viên.

- Cơ hội đào tạo và thăng tiến: Lãnh đạo công ty cần chú trọng cơ hội này đối với người lao động đặc biệt là những người có năng lực, muốn gẳn bó lâu dài với công ty. Tạo điều kiện cho họ được nâng cao khả năng nghề nghiệp và chuyên môn thông qua các lớp đào tạo ngắn hạn và dài hạn. - Điều kiện làm việc: Ngành nghề hoạt động của công ty là sản xuất và kinh doanh thép, các công việc nặng nhọc, do đó cần trang bị đầy đủ các dụng cụ bảo hộ lao động cho công nhân, môi trường làm việc thoáng mát đặc biệt là mùa hè.

- Tính ổn định công việc: Đây là nỗi lo của người lao động trước cuộc cách mạng 4.0 đang và sẽ diễn ra ở Việt Nam trong những năm tới. Do vậy, Ban lãnh đạo cần bố trí sắp xếp lao động hợp lý, không ngừng mở rộng thị trường để mở rộng sản xuất kinh doanh giúp người lao động ổn định công việc.

\section{Lò̀i cảm ơn}

Nghiên cứu này được tài trợ bởi Trung tâm Nghiên cứu Úng dụng Khoa học và Công nghệ, Trường Đại học Sư phạm kỹ thuật Hưng Yên mã số đề tài UTEHY.T006.P1718.05.

\title{
Tài liệu tham khảo
}

[1]. Trần Thị Kim Dung, Đo lường mức độ thỏa mãn đối với công việc trong điều kiện của Việt Nam, Tạp chí phát triển khoa học công nghệ, 2005, Đại học quốc gia TP.Hồ Chí Minh, số 12, tr. 85-91.

[2]. Hoàng Gia Khánh Giao và Bùi Nhất Vương, Ảnh hưởng của các yếu tố văn hóa doanh nghiệp đến sự gắn bó với tổ chức của nhân viên công ty cổ phần CMC Telecom tại Thành phố Hồ Chí Minh. [3]. Cảnh Chí Hoàng, Các yếu tố ảnh hưởng đên sự gắn kết của nhân viên với kho bạc nhà nước Thành Phố Hồ Chí Minh. Tạp chí Tài chính, tháng 10/2016.

[4]. Lê Thị Phương Thảo, Các nhân tố ảnh hưởng đển sự gắn bó của nhân viên tại công ty Scavi Huế. Tạ chí Kinh tế và dư báo, 2015, chuyên đề số 4, tr. 78-80.

[5]. Hồ Huy Tựu và Phạm Hồng Liêm, Sự gắn bó của nhân viên đối với công ty du lịch Khánh Hòa. Tạp chí Phát triển kinh tế, 2012, số 264, tháng 10, tr. 56-64.

[6]. Nguyễn Thành Tuyến và Lê Kim Long, Phân tích các nhân tố tác động đến sự gắn kết của nhân viên đôi với Tổng công ty Khánh Việt. Tạp chí Khoa học - công nghệ Thủy sản, 2014, số 1.

[7]. Bùi Thị Minh Thu, Lê Nguyễn Anh Khôi, Nghiên cứu các nhân tố ảnh hưởng đến lòng trung thành của nhân viên Tồng công ty lắp máy Việt Nam (LILAMA). Tạp chi khoa học, đại học Mở Thành phổ Hồ Chí Minh, 2016, số 3, tr. 90-103.

[8]. Natile J. Allen. John P. Meyer, The measurement and antecedents of affective, continuance and normative commitment to the organization. Journal of Occupational and Organizational Psychology, 1990.

[9]. Slack, F.J \&Orife, J.N \&Anderson, F.P, Effects of commitment to Corporate Vision on Employee Satisfaction with their Organization. An Empirical study in the United states. International Journal of management, 2010, Vol. 27 (3), pp. 421-436.

[10]. Mowday, R.T., Steers, R.M \&Porter, L.W., The Measurement of Organization Commitment. Journal of Vocational Behavior, 1979, Vol. 14, pp. 224-274.

[11]. Porter, L.W., Steer, R.M, Monday, R.T.,\&Boulian, P.V, “Organizational Commitment, Job Satisfaction, and Turnover among Psychiatric", 1974.

\section{FACTORS AFFECTING THE MEMBERSHIP OF EMPLOYEES WITH ORGANIZATION: EXPERIMENTAL RESEARCH IN DONG A STEEL TRADING AND MANUFACTURING CO., LTD.}

\begin{abstract}
:
This research underlined analyses of some factors that affect the staff's loyalty the Dong A steel trading and manufacturing co., Research data were collected through the questionnaire survey of 230 staff members. The study used a reliability test using Cronbach's alpha coefficient, Factor analysis and regression analysis. Results show that the level of engagement of employees with the company depends on four factors: income and welfare, opportunities for training and promotion, working conditions and job stability. Income and welfare factors have the strongest impact on the company's staff.
\end{abstract}

Keywords: Employee Commitment. 
Phụ lục 01. Kiểm định thang đo các biến độc lập

Reliability Statistics

\begin{tabular}{|r|r|}
\hline Cronbach's Alpha & N of Items \\
\hline .872 & 32 \\
\hline
\end{tabular}

Item-Total Statistics

\begin{tabular}{|c|c|c|c|c|}
\hline & $\begin{array}{l}\text { Trung bình thang } \\
\text { đo nểu loại biến } \\
\text { (Scale Mean if } \\
\text { Item Deleted) }\end{array}$ & $\begin{array}{l}\text { Phương sai thang } \\
\text { đo nếu loại biến } \\
\text { (Scale Variance } \\
\text { if Item Deleted) }\end{array}$ & $\begin{array}{l}\text { Tương quan biến } \\
\text { tồng (Corrected } \\
\text { Item-Total } \\
\text { Correlation) }\end{array}$ & $\begin{array}{l}\text { Cronbach's Alpha } \\
\text { nếu loại biến } \\
\text { (Cronbach's Alpha } \\
\text { if Item Deleted) }\end{array}$ \\
\hline $\begin{array}{l}\text { 1. Công việc hiện tại phù hợp với năng } \\
\text { lực cá nhân của tôi }\end{array}$ & 128.13 & 157.437 & .374 & .869 \\
\hline $\begin{array}{l}\text { 2. Công việc hiện tại phù hợp với kỹ } \\
\text { năng và trình độ chuyên môn của tôi }\end{array}$ & 128.10 & 153.896 & .541 & .865 \\
\hline $\begin{array}{l}\text { 3. Trách nhiệm và quyền lợi trong } \\
\text { công việc của tôi tương xứng với nhau }\end{array}$ & 128.12 & 159.670 & .282 & .871 \\
\hline $\begin{array}{l}\text { 4. Công việc của tôi có nhiều thách } \\
\text { thức, thú vị }\end{array}$ & 127.96 & 159.482 & .333 & .870 \\
\hline 5. Tôi hiểu rõ về công việc đang làm & 127.77 & 158.087 & .410 & .868 \\
\hline 6. Khối lượng công việc của tôi hợp lý & 127.92 & 159.562 & .329 & .870 \\
\hline $\begin{array}{l}\text { 7. Tôi được tham gia các khóa đào tạo } \\
\text { cần thiết để nâng cao hiệu quả làm } \\
\text { việc }\end{array}$ & 128.22 & 152.644 & .552 & .865 \\
\hline $\begin{array}{l}\text { 8. Tôi được tạo điều kiện học tập để } \\
\text { nâng cao trình độ }\end{array}$ & 128.15 & 158.976 & .294 & .871 \\
\hline $\begin{array}{l}\text { 9. Nơi tôi làm việc luôn có cơ hội } \\
\text { thăng tiến cho người có năng lực }\end{array}$ & 127.96 & 159.749 & .315 & .870 \\
\hline $\begin{array}{l}\text { 10. Chính sách đào tạo và thăng tiến } \\
\text { nơi tôi làm việc công bằng }\end{array}$ & 127.77 & 156.838 & .474 & .867 \\
\hline $\begin{array}{l}\text { 11. Tôi được tự đánh giá và khẳng } \\
\text { định năng lực bản thân }\end{array}$ & 127.92 & 159.421 & .330 & .870 \\
\hline $\begin{array}{l}\text { 12. Lãnh đạo của tôi luôn ghi nhận ý } \\
\text { kiến đóng góp của nhân viên }\end{array}$ & 128.21 & 153.010 & .540 & .865 \\
\hline $\begin{array}{l}\text { 13. Lãnh đạo của tôi đối xử công } \\
\text { bằng, quan tâm đến nhân viên }\end{array}$ & 128.11 & 158.899 & .322 & .870 \\
\hline 14. Đồng nghiệp của tôi rất thân thiện & 127.94 & 159.925 & .316 & .870 \\
\hline 15. Đồng nghiệp của tôi đáng tin cậy & 127.73 & 157.000 & .473 & .867 \\
\hline $\begin{array}{l}\text { 16. Đồng nghiệp của tôi sẵng sàng } \\
\text { giúp đỡ lẫn nhau và phối hợp tốt trong } \\
\text { công việc }\end{array}$ & 127.88 & 160.115 & .305 & .871 \\
\hline $\begin{array}{l}\text { 17. Nhân viên luôn nhận được sự hỗ } \\
\text { trợ của lãnh đạo trong công việc }\end{array}$ & 128.22 & 152.659 & .550 & .865 \\
\hline $\begin{array}{l}\text { 18. Lãnh đạo của tôi tạo cơ hội thăng } \\
\text { tiến cho người có năng lực }\end{array}$ & 128.14 & 159.304 & .297 & .871 \\
\hline $\begin{array}{l}\text { 19. Tiền lương tôi được trả phù hợp } \\
\text { với năng lực và đóng góp của tôi }\end{array}$ & 127.95 & 159.380 & .334 & .870 \\
\hline $\begin{array}{l}\text { 20. Tiền thưởng tôi nhận được xứng } \\
\text { đáng với hiệu quả làm việc của tôi }\end{array}$ & 127.76 & 157.003 & .472 & .867 \\
\hline $\begin{array}{l}\text { 21. Tôi được cung cấp đầy đủ chế độ } \\
\text { bảo hiểm xã hội, bảo hiểm y tế }\end{array}$ & 127.92 & 159.350 & .331 & .870 \\
\hline $\begin{array}{l}\text { 22. Tôi được hưởng đầy đủ các chế độ } \\
\text { nghĩ phép, nghĩ lê̂, tham quan du lịch, } \\
\text { khám sức khỏe định kỳ... }\end{array}$ & 128.20 & 152.916 & .541 & .865 \\
\hline 23. Thời gian làm việc của tôi hợp lý & 128.13 & 158.978 & .298 & .871 \\
\hline
\end{tabular}


ISSN 2354-0575

\begin{tabular}{|l|r|r|r|r|}
\hline $\begin{array}{l}\text { 24. Tôi làm việc trong điều kiện an } \\
\text { toàn }\end{array}$ & 127.92 & 160.123 & .309 & .870 \\
\hline $\begin{array}{l}\text { 25. Tôi được tham gia các khóa huấn } \\
\text { luyện về an toàn lao động định kỳ } \\
\text { (như kỹ thuật phòng cháy chữa cháy, } \\
\text { kỹ thuật an toàn về điện...) }\end{array}$ & 127.72 & 157.848 & .436 & .868 \\
\hline $\begin{array}{l}\text { 26. Áp lực công việc của tôi không } \\
\text { quá cao }\end{array}$ & 127.92 & 159.508 & .325 & .870 \\
\hline $\begin{array}{l}\text { 27. Môi truờng làm việc sạch sẽ, đảm } \\
\text { bảo vệ sinh }\end{array}$ & 128.23 & 153.278 & .524 & .865 \\
\hline $\begin{array}{l}\text { 28. Tôi làm việc trong môi trường đầy } \\
\text { đủ tiện nghi hồ trợ cho công việc }\end{array}$ & 128.15 & 159.453 & .274 & .872 \\
\hline 29. Tôi ít phải lo lắng bị mất việc làm & 127.94 & 160.112 & .304 & .871 \\
\hline $\begin{array}{l}\text { 30. Đa số người lao động tại đều được } \\
\text { ký hợp đồng lao động không xác định } \\
\text { thời hạn }\end{array}$ & 127.76 & 157.134 & .466 & .867 \\
\hline $\begin{array}{l}\text { 31. Tôi được đảm bảo có việc làm } \\
\text { thường xuyền }\end{array}$ & 127.93 & 159.804 & .311 & .870 \\
\hline $\begin{array}{l}32 . \text { Nơi tôi đang làm việc hoạt động } \\
\text { rât ồn định và có hiệu quả }\end{array}$ & 128.21 & 152.939 & .540 & .865 \\
\hline
\end{tabular}

Phụ lục 02. Kiểm định thang đo các biến phụ thuộc

Reliability Statistics

\begin{tabular}{|r|r|}
\hline Cronbach's Alpha & N of Items \\
\hline .898 & 5 \\
\hline
\end{tabular}

Item-Total Statistics

\begin{tabular}{|l|r|r|r|r|}
\hline & $\begin{array}{c}\text { Trung bình thang } \\
\text { đo nếu loại biến } \\
\text { (Scale Mean if Item } \\
\text { Deleted) }\end{array}$ & $\begin{array}{c}\text { Phương sai thang } \\
\text { đo nếu loại biến } \\
\text { (Scale Variance if } \\
\text { Item Deleted) }\end{array}$ & $\begin{array}{c}\text { Tương quan biến } \\
\text { tổng (Corrected } \\
\text { Item-Total } \\
\text { Correlation) }\end{array}$ & $\begin{array}{c}\text { Cronbach's Alpha } \\
\text { nếu loại biê̂n } \\
\text { (Cronbach's Alpha } \\
\text { if Item Deleted) }\end{array}$ \\
\hline $\begin{array}{l}\text { 1. Thật khó rời khỏi công ty } \\
\text { này ngay cả khi muốn }\end{array}$ & 17.69 & 4.942 & .906 & .838 \\
\hline $\begin{array}{l}\text { 2. Cảm thấy công ty như là } \\
\text { ngôi nhà thứ hai của mình }\end{array}$ & 17.58 & 5.641 & .714 & .883 \\
\hline $\begin{array}{l}\text { 3. Hạnh phúc khi sử dung thời } \\
\text { gian làm việc đến cuối đời với } \\
\text { công ty }\end{array}$ & 17.51 & 6.402 & .524 & .919 \\
\hline $\begin{array}{l}\text { 4. Cuộc sống sẽ xáo trộn nếu } \\
\text { rời bỏ công ty ngay bây giờ. }\end{array}$ & 17.61 & & .714 & .883 \\
\hline $\begin{array}{l}\text { 5. Công ty xứng đáng với } \\
\text { lòng trung thành }\end{array}$ & 17.68 & 5.528 & & .841 \\
\hline
\end{tabular}

